\title{
A measure of persistence in daily pound exchange rates
}

Article

Accepted Version

Brooks, C. (1995) A measure of persistence in daily pound exchange rates. Applied Economics Letters, 2 (11). pp. 428431. ISSN 1466-4291 doi:

https://doi.org/10.1080/135048595356998 Available at https://centaur.reading.ac.uk/35993/

It is advisable to refer to the publisher's version if you intend to cite from the work. See Guidance on citing.

Published version at: http://dx.doi.org/10.1080/135048595356998

To link to this article DOI: http://dx.doi.org/10.1080/135048595356998

Publisher: Taylor \& Francis

All outputs in CentAUR are protected by Intellectual Property Rights law, including copyright law. Copyright and IPR is retained by the creators or other copyright holders. Terms and conditions for use of this material are defined in the End User Agreement.

\section{www.reading.ac.uk/centaur}

\section{CentAUR}

Central Archive at the University of Reading

Reading's research outputs online 
This is an Author's Accepted Manuscript of an article published in Applied Economics Letters (1995) [copyright Taylor \& Francis], available online at:

http://www.tandfonline.com/10.1080/135048595356998 


\title{
A Measure of Persistence in Daily Pound Exchange Rates
}

\author{
by
}

\section{Chris Brooks}

Department of Economics, Faculty of Letters and Social Sciences, The University of Reading, P.O. Box 218, Whiteknights, Reading, Berks. RG6 6AA Fax Number: (+44) 1734316533

\begin{abstract}
An alternative procedure to that of Lo (1991) is proposed for assessing whether there is significant evidence of persistence in time series. The technique estimates the Hurst exponent itself, and significance testing is based on an application of bootstrapping using surrogate data. The method is applied to a set of ten daily Pound exchange rates. A general lack of long-term memory is found to characterise all the series tested in sympathy with the findings of a number of other recent papers which have used Lo's techniques.
\end{abstract}




\section{INTRODUCTION}

Numerous recent papers have sought to test for the presence of long-term periodic or nonperiodic cycles in financial time series data using a variety of techniques, with generally inconclusive results to date. Engel and Hamilton (1990), for example, find persistence in a set of quarterly Dollar foreign exchange series. Booth et al. (1982) use "classical" rescaled range analysis on the German Mark, French Franc, and British Pound (all against the Dollar) and find persistence over the flexible regime period (July 1965-June 1971), but antipersistence in the fixed regime (July 1973-June 1979). DeGrawe et al. (1993) find a similar result with estimated values of the Hurst exponent of around 0.62 across three Dollar-currencies, although neither of sets of authors use a methodology which is robust to autocorrelation or attempt any tests of significance. Lo (1991), however, finds no evidence for persistence in U.S. stock data using the robust adjusted rescaled range analysis which he proposes. This is confirmed by Mills (1993), using FTA All Share data, and by Brookfield (1995) using both U.K. FTA-500 returns data, and the squares and absolute values of the returns. Whilst a finding of persistence is not necessarily inconsistent with market efficiency, it must question the random walk model as being an accurate representation of the data.

The purposes of this paper are twofold. First, to highlight a number of possible limitations of Lo's (1991) approach to rescaled range analysis, and to outline an alternative which may overcome these difficulties. Second, to consider whether applying this autocorrelation robust method to a diverse set of foreign exchange rates yields a comparable lack of persistence to that described above in stock markets.

\section{RESCALED RANGE ANALYSIS AND THE HURST EXPONENT}


The Hurst Exponent (Hurst, 1951) was originally suggested as a result of a study of the flow of water through dams, and stems from the observation that particles suspended in fluid move erratically, commonly known as Brownian motion. Recently the technique has been popularised in economics by Peters (1994, 1991a, 1991b). H, the Hurst exponent, can be calculated as follows (Peters, 1994). Let $\bar{x}$ denote the mean of a time series of length T, and $\mathrm{S}_{\mathrm{t}}$ denote the estimated (ML) standard deviation. The data is first rescaled to have a mean of zero by subtracting the mean, $\bar{x}$, from each observation. A cumulative series is then created by adding each of the rescaled sample from the second observation onwards in turn to the first rescaled observation

$$
Y_{j}=\left(\left(x_{1}-\bar{x}\right)+\left(x_{j}-\bar{x}\right)\right)
$$

and the adjusted range is calculated as

$$
R_{n}=\left[\max _{l \leq k \leq n} \sum_{j=1}^{k}\left(Y_{j}-\bar{Y}_{n}\right)-\min _{l \leq k \leq n} \sum_{j=1}^{k}\left(Y_{j}-\bar{Y}_{n}\right)\right]
$$

This leads to the formula

$$
\left(R_{n} / S_{n}\right)=c . n^{H}
$$

where $R_{n}$ is the adjusted range, $S_{n}$ is the estimated standard deviation of the sample, $c$ is a constant, and $\mathrm{H}$ denotes the Hurst exponent. $\left(R_{n} / S_{n}\right)$ is known as the rescaled range, denoted as $\widetilde{Q}_{n}$. If we take the logarithm of equation (3), we obtain

$$
\log (R / S)_{n}=\log (c)+H \log (n)
$$

and hence in practice the Hurst exponent can be calculated by plotting $\log (R / S)_{n}$ against $\log (n)$ and estimating the slope over a judiciously chosen linear region by OLS. The interpretation of the Hurst exponent is one of the length of "memory" of the series. A Hurst exponent of 0.5 signifies a random process; $0.5<\mathrm{H} \leq 1$ implies a persistent time series which displays long memory effects, while $0 \leq \mathrm{H}<0.5$ implies an antipersistent process, reversing previous changes more frequently than would a truly random process. A persistent series is 
akin to the concept of trend reinforcement, while an antipersistent one is akin to mean reversion ${ }^{\mathrm{i}}$.

In a recent paper, Lo (1991) recommends a modification of the "classical" rescaled range statistic in order to account for possible biases which may result from short term dependence in the series under consideration. Short-term dependence may encourage a spurious rejection of the null of no memory to a degree which reflects the magnitude and direction of the short term autocorrelation, although the effects are minimised in large samples such as those used here (Booth et al., 1982). The numerator of the test statistic remains unchanged, but the denominator is augmented by the addition of a term which reflects the magnitude of autocovariances in the series. The augmented numerator is given by

$Q_{n}=\frac{R_{n}}{\hat{\sigma}_{n}}$

where $\hat{\sigma}_{n}=S_{n}+2 \sum_{j=1}^{q} \omega_{j}(q)\left[\sum_{i=j+1}^{n}\left(x_{i}-\bar{x}_{n}\right)\left(x_{i-j}-\bar{x}_{n}\right)\right], \omega_{j}(q) \equiv 1-\frac{j}{q+1}, q<n$

There are, however, a number of potential drawbacks from using Lo's approach. First, Lo recommends concentration on the $(R / S)_{n}$ statistic itself rather than on the Hurst exponent since there is an inherent bias in the estimation procedure of the latter, although Wallis and Matalis (1970) find this to be generally very small. The rescaled range statistic itself has no immediate intuitive interpretation. The Hurst exponent, however, can be viewed as a direct measure of the extent of persistence in a system, since it is connected to the coefficient $d$ of fractional integration in an ARFIMA representation via the simple relationship

$$
H=d+0.5
$$


Preliminary results suggest a close approximation to the estimated value of $d$ using the Geweke Porter-Hudak spectral procedure. Second, apart from Lo's suggestion based on the frequency of the data, there is no obvious method of selecting the optimal value of the lag truncation parameter, $q$, and although Lo's results are not qualitatively sensitive to the choice of $q$, they are in Brookfield (1995) and Caporale et al.(1994). Lo's own Monte Carlo simulations show that the power of the test statistic against fractionally integrated processes is considerably reduced as $q$ is increased, even at large sample sizes. As Booth et al. (1982) point out, there is extremely little linear dependence in many financial time series of log-returns, so that augmentation to remove short term dependence should, in theory at least, make very little difference to the outcome.

An alternative procedure for testing for persistence in time series is available, and is based on calculation of the Hurst exponent itself. Peters (1994) suggests an approach where short term dependence is filtered from the series by estimating an $\operatorname{AR}(p)$ model, and calculating the exponent using the estimated residuals from the linear fit. $p$ may be selected using Akaike's (1974) or Schwarz's (1978) information criterion, or some other method. This will have the advantage of removing dependence of a specific form which is under the control of the user. Peters' technique is then to apply a test of significance based on rules he develops using Monte Carlo simulations. A major drawback of this approach, however, is that it relies on the assumption of Gaussianity, although this is not required by classical rescaled range analysis itself (Mandelbrot and Wallis, 1969); this assumption is likely to be rejected for the vast majority of financial time series.

\section{THE USE OF SURROGATE DATA}


Bootstrap significance tests can be undertaken using the method of surrogate data (e.g. Theiler, 1991; Rapp et al., 1993). This method provides an alternative to those of Peters and Lo, which is robust to non-normality and short-term autocorrelation in the original data. A randomised data set with the same distribution and autocorrelation structure as the original data is created. Technically, this is achieved by taking the Fourier transform of the original series, randomising the phases, and taking the inverse Fourier transform. The autocorrelation structure is preserved, so that the surrogate data set has the same level of short-term linear dependence as the original, but all traces of long-term dependence have been removed. Hence, given a positive result in a test for persistence, one can use the method of surrogate data to determine if the dependence is of a long-term form, or can simply be attributed to short -term autocorrelation. If the positive result is still apparent in a test on the surrogate data, then the result is likely to be due to short-term linear dependence in the data, but if the results between the two data sets differ, this must be due to long-term persistence or antipersistence in the raw data which by definition is not present in the surrogate data. Creating multiple surrogate data sets enables one to use the method of bootstrapping (Efron, 1979) to create confidence intervals and to undertake tests of significance for the estimated test statistics ${ }^{\text {ii }}$. The test statistic for the bootstrap significance test suggested by Theiler et al. (1992) is given in this case by

$$
S=\left|\frac{H_{\text {data }}-<H_{\text {surrogate }}>}{\sigma(H)_{\text {surrogate }}}\right|
$$

Where $<H_{\text {surrogate }}>$ is the mean of the test statistic for the surrogate data, and $\sigma(H)_{\text {surrogate }}$ is its standard deviation. Theiler et al. suggest that a value of $S \approx 2$ is not significant, but $S$ $\approx 10$ is highly significant. Clearly this technique is extremely useful in answering the question of whether the results from the actual data are statistically significantly different 
from those of the surrogate data, and when we can assume no formal distribution for the underlying test statistic ${ }^{\mathrm{iii}}$.

\section{THE DATA AND RESULTS}

The analysis undertaken in this paper is based on just over twenty years of daily mid-price spot exchange rate data, denominated in Pound-Sterling. The sample period taken covers the entire post-Bretton Woods era of floating exchange rates, specifically from 2 January 1974 until 1 July 1994 inclusive. The raw exchange rates were transformed into logreturns, which constituted a series of 5191 observations.

The results of table 1 show that long memory is generally lacking from all of the series. Although the estimated value of $\mathrm{H}$ is always greater than 0.5 for the returns data, and typically around 0.6 , it tends to be reduced somewhat on removal of the linear components using an autoregressive filter of length $p$ chosen by Akaike's information criterion (Akaike, 1974) and of an arbitrary ten lags, which should be more than enough to capture any short term dependence in the series. Furthermore, as shown by table 2, the average Hurst exponent of the surrogate data is only marginally lower than that of the filtered data. This can be tested more formally using Theiler's bootstrap significance technique. With the possible exception of the U.S. Dollar, it can be seen that the estimated value of the Hurst exponent is not significantly different between the surrogate and original data. Thus it appears that none of the series exhibit long term persistence. Application of an identical procedure to the squared residuals of an $\operatorname{AR}(p)$ model (not shown but available from the author) yields quite different results. There exists a highly significant degree of long memory in the squared data, although this is by no means a sufficient condition for the IGARCH parameterisation of Engle and Bollerslev (1986) 


\section{CONCLUSIONS}

The results obtained by applying a bootstrapping technique to the estimation of the Hurst exponent indicate a lack of long memory in the mean of all the series investigated. Although the technique is quite different in formulation to that of Lo, it appears to generate a result similar to that of many recent empirical studies of this phenomenon.

One may conjecture that, a priori, that those currencies which are less frequently traded or traded in smaller quantities (such as the Austrian Schilling or Danish Krone) may exhibit a stronger degree of serial dependence than those which are traded more frequently (such as the U.S. Dollar or German Mark), since a closer examination of the latter by analysts and dealers should imply that any possible persistence which results in profit opportunities would be quickly arbitraged away. The finding of this study is that this hypothesis is rejected, with lesser-traded currencies being no more likely to deviate from a random walk in the long term than those which are more frequently traded.

\section{ACKNOWLEDGEMENTS}

I would like to thank Olan Henry for providing useful comments on an earlier version of this paper, whilst absolving him from responsibility for any remaining errors.

\section{REFERENCES}

Akaike, H. (1974) A New Look at the Statistical Model Identification, IEEE Transactions on Automatic Control, AC-19(6), 716-723

Booth, G.G., Kaen, F.R. and Koveos, P.E. (1982) R/S Analysis of Foreign Exchange Rates Under Two International Monetary Regimes, Journal of Monetary Economics, 10, 407-415 
Brookfield, D. (1995) New Evidence Regarding the Statistical Properties of the FTA500 U.K. Stock Market Index, Applied Economics Letters, 2, 110-112

Caporale, G.M., Kalyvitis, S. and Pittis, N. (1994) Persistence in Real Variables Under Alternative Exchange Rate Regimes: Some Multi-Country Evidence, Economics Letters, 45, 93-102

De Grauwe, P., Dewachter, H. and Embrechts, M. (1993) Exchange Rate Theory: Chaotic Models of Foreign Exchange Markets Blackwell, Oxford

Efron, B. (1979) Bootstrap Methods: Another Look at the Jackknife, Annals of Statistics, 7(1), 1-26

Engel, C. and Hamilton, J.D. (1990) Long Swings in the Dollar: Are they in the Data and Do Markets Know It? American Economic Review, 80(4), 689-713

Engle, R.F. and Bollerslev, T. (1986) Modelling the Persistence of Conditional Variances, Econometric Reviews, 5(1), 1-50

Geweke, J. and Porter-Hudak, F. (1983) The Estimation and Application of Long Memory Time Series Models, Journal of Time Series Analysis, 4, 221-238

Hurst, H.E. (1951) The Long-Term Storage Capacity of Reservoirs, Transactions of the American Society of Civil Engineers, 116, 770-799

Lo, A.W. (1991) Long-Term Memory in Stock Market Prices, Econometrica, 59(5), 12791313

Mills, T.C. (1993) Is There Long-Term Memory in U.K. Stock Returns, Applied Financial Economics, 3, 303-306

Peters, E.E. (1994) Fractal Market Analysis: Applying Chaos Theory to Investment and Economics, John Wiley \& Sons, New York

Peters, E.E. (1991a) A Chaotic Attractor for the S\&P 500 Financial Analysts Journal, March-April, 55-62 
Peters, E.E. (1991b) Chaos and Order in the Capital Markets, Wiley and Sons, New York

Rapp, P.E., Albano, A.M., Schmah, T.I. and Farwell, L.A. (1993) Filtered Noise can Mimic Low-Dimensional Chaotic Attractors, Physical Review E, 47(4), 2289-2297

Schwarz, G. (1978) Estimating the Dimension of a Model, Annals of Statistics, 6, 461-464

Theiler, J., Galdrikian, B., Longtin, A., Eubank, S. and Farmer, J.D. (1992) Using Surrogate Data to Detect Nonlinearity in Time Series Nonlinear Modelling and Forecasting (Ed.) Casdagli, M. and Eubank, S. pp 163-188, Addison-Welsley, Reading, Mass.

Wallis, J.R. and Matalis, N.C. (1970) Small Sample Properties of H and K - Estimators of the Hurst Coefficient $h$, Water Resources Research, 6, 1583-1594 
Table 1: Values of Hurst Exponent, H, for the Raw Data, the Mean of the Surrogates, and the Residuals of $\operatorname{AR}(p)$ and $\operatorname{AR}(10)$ Models

\begin{tabular}{||c|c|c||c|c||}
\hline Series & Original series & mean of surrogates & Residuals of AR $(p)$ & Residuals of AR(10) \\
\hline Austrian Schilling & 0.6181 & 0.5635 & 0.6172 & 0.5744 \\
\hline Canadian Dollar & 0.6038 & 0.5581 & 0.5973 & 0.5896 \\
\hline Danish Krone & 0.6196 & 0.5599 & 0.6264 & 0.5841 \\
\hline French Franc & 0.6208 & 0.5713 & 0.5947 & 0.5775 \\
\hline German Mark & 0.6184 & 0.5554 & 0.6112 & 0.5691 \\
\hline Hong Kong Dollar & 0.6158 & 0.5645 & 0.6095 & 0.5909 \\
\hline Italian Lira & 0.5997 & 0.5650 & 0.5957 & 0.5899 \\
\hline Japanese Yen & 0.5621 & 0.5571 & 0.5342 & 0.5276 \\
\hline Swiss Franc & 0.5900 & 0.5639 & 0.5920 & 0.5745 \\
\hline U.S. Dollar & 0.6260 & 0.5609 & 0.6157 & 0.6020 \\
\hline \hline
\end{tabular}


Table 2: The Value of $H$, the Hurst Exponent together with an Implementation of Theiler's Bootstrap Significance Test

\begin{tabular}{|c|c|c|c|c|c|c|c|c|c|c|}
\hline Series & $\begin{array}{l}\text { Austrian } \\
\text { Schilling }\end{array}$ & $\begin{array}{c}\text { Canadian } \\
\text { Dollar }\end{array}$ & $\begin{array}{l}\text { Danish } \\
\text { Krone }\end{array}$ & $\begin{array}{l}\text { French } \\
\text { Franc }\end{array}$ & $\begin{array}{c}\text { German } \\
\text { Mark }\end{array}$ & $\begin{array}{c}\text { Hong Kong } \\
\text { Dollar }\end{array}$ & $\begin{array}{c}\text { Italian } \\
\text { Lira }\end{array}$ & $\begin{array}{c}\text { Japanese } \\
\text { Yen }\end{array}$ & $\begin{array}{l}\text { Swiss } \\
\text { Franc }\end{array}$ & $\begin{array}{c}\text { U.S. } \\
\text { Dollar }\end{array}$ \\
\hline \multicolumn{11}{|c|}{ Real Data } \\
\hline$H$ & 0.618 & 0.604 & 0.620 & 0.621 & 0.618 & 0.616 & 0.600 & 0.562 & 0.590 & 0.626 \\
\hline \multicolumn{11}{|c|}{ Surrogate Data } \\
\hline mean $(H)$ & 0.563 & 0.558 & 0.560 & 0.571 & 0.555 & 0.565 & 0.565 & 0.557 & 0.564 & 0.561 \\
\hline$\sigma(H)$ & 0.019 & 0.017 & 0.019 & 0.016 & 0.025 & 0.016 & 0.018 & 0.018 & 0.017 & 0.016 \\
\hline \multicolumn{11}{|c|}{ Test Statistic } \\
\hline$S(H)$ & 2.867 & 2.660 & 3.178 & 3.186 & 2.500 & 3.176 & 1.918 & 0.282 & 1.539 & 4.042 \\
\hline
\end{tabular}


${ }^{i}$ although as Peters (1994) points out, this assumes that that the process has a well defined mean, which may not necessarily be the case.

${ }^{i i}$ As a consequence of computational constraints, and the consideration that a large number of series were to be tested each with a large number of observations, only 20 surrogate data series were created for each original series for comparison with the real data. Many applications in the natural sciences have found this to be adequate.

iii The technique would be of limited value, however, where the asymptotic distribution of the test statistic under the null is known, since a far more powerful test can be undertaken using that distribution (for example, in the case of the BDS test of Brock, Dechert and Scheinkman, 1987). 